\title{
Uma análise do hino "EU cuido de TI" com base na teoria da linguística sistêmico-funcional e do sistema de avaliatividade
}

\section{An analysis of the hymn "I take care of IT" based on theory of systemic-functional linguistics and the appraisal system}

\author{
Gilca Sônia Correia Borges ${ }^{1}$ \\ Fabíola Aparecida Sartin Dutra Parreira ${ }^{2}$
}

Recebido em: 25/09/2020
Aprovado em: $15 / 12 / 2020$
Publicado em: 20/12/2020

RESUMO: Este artigo objetiva investigar as escolhas léxico-gramaticais realizadas no hino "Eu cuido de ti", de autoria da cantora e compositora gospel, Cláudia Canção. Para tanto, utilizaremos o arcabouço da Linguística Sistêmico-Funcional, fundamentada nos estudos desenvolvidos por Halliday (1994), e de seus seguidores Halliday e Matthiessen (2004), Fuzer e Cabral (2014), Martin e White (2005), Almeida (2010), Ikeda (2010), Nunes e Cabral (2013), dentre outros. O fio condutor das análises é o sistema de avaliatividade, com ênfase no subsistema de atitude. A metodologia constou em: realizar a leitura do hino "Eu cuido de ti", selecionar as principais avaliações e em seguida categorizar de acordo com o subsistema de atitude. Os resultados apontam significados sobre a representação social do "ser cristão" na sociedade atual de acordo com os elementos avaliativos existentes nos excertos selecionados.

Palavras-chave: Linguística Sistêmico-Funcional; Sistema de Avaliatividade; Representação Social.

\begin{abstract}
This article aims to investigate the lexical-grammatical choices made in the hymn "I take care of you", written by a gospel singer and songwriter, Cláudia Canção. For this, we will use the framework of Systemic-Functional Linguistics, grounded in the studies developed by Halliday (1994), and his followers Halliday and Matthiessen (2004), Fuzer and Cabral (2014), Martin and White (2005), Almeida (2010), Ikeda (2010), Nunes and Cabral (2013), among others. The guiding thread of the analyzes is the appraisal system, with an emphasis on the subsystem of attitude. The methodology consisted of reading the hymn "I take care of you", selecting the main evaluations and then categorizing, according to the attitude subsystem. The results point out meanings about the social representation of "being a Christian" in today's society, according to the evaluative elements existing in the selected excerpts.
\end{abstract}

Keywords: Systemic-Functional Linguistics; Appraisal System; Social Representation.

1. Graduação em Ciências e Biologia pela Universidade Estadual de Goiás. Graduação em Pedagogia. Especialização em Psicopedagogia Institucional e Clínica. Mestranda em Estudos da Linguagem pelo Programa de Pós-graduação Mestrado e Doutorado em Estudos da Linguagem (PPGEL). Professora - biologia - Secretaria de Estado de Educação, Cultura e Esporte e professora piv- Secretaria de Estado de Educação, Cultura e Esporte. ORCID: 0000-0002-7639-6721 E-mail: gilcasonia@gmail.com

2. Graduação em Letras - Português - Inglês. Mestrado em Letras - Linguística e Língua Portuguesa. Professora adjunta do Departamento de Letras da UFG - Universidade Federal de Goiás e professora permanente do Programa de Mestrado em Estudos da Linguagem. Orienta pesquisas na área de formação de professores e análise do discurso Sistêmico-Funcional, mais especificamente, com o foco no estudo da avaliação na linguagem - sistema de avaliatividade - Appraisal System.ORCID: 0000-0002-6122-4038 E-mail: fabiolasartin@gmail.com 
BORGES, G.S.C.; PARREIRA, F.A.S.D.

\section{INTRODUÇÃO}

A Linguística Sistêmico-Funcional, doravante LSF é uma teoria desenvolvida pelo linguista britânico Michael A. K. Halliday (1994), com base nas ideias do linguista J. R. Firth $(1890$ - 1960). Firth deu início às primeiras sistematizações a partir do trabalho do antropólogo B. Malinowski (1884-1932) que reconhecia a língua como "uma das mais importantes manifestações da cultura de um povo" (FUZER; CABRAL, 2014, p.17), tendo desenvolvido sua teoria considerando a relação entre a língua e o seu uso em contexto.

Essa teoria está articulada com a noção dos estudos funcionalistas da linguagem, ou seja, permite uma análise paradigmática e não somente sintagmática da língua em uso. Assim sendo, tornou-se conhecida por conceber a língua de forma "holística e contextual" (VIAN Jr., 2010), constituída por meio de "sistemas léxico-gramaticais interligados" com uma base funcional para produzir significados em um meio de comunicação (SANTOS, 2009, p. 166).

Dessa forma, também há a necessidade de se compreender, como apontam Fuzer e Cabral (2014, p. 19), que "cada sistema é um conjunto de alternativas possíveis que podem ser semânticas, léxico-gramaticais ou fonológicas e grafológicas". A LSF pode ser descrita segundo (BARBARA; DE MACEDO, 2009, p. 89) como uma teoria social e semiótica pelas características que apresenta:

A LSF é caracterizada como uma teoria social porque parte da sociedade e da situação de uso para o estudo da linguagem; seu foco está em entender como se dá a comunicação entre os homens, a relação, os indivíduos e desses com a comunidade. Caracteriza-se também como uma teoria semiótica porque se preocupa com a linguagem em todas as suas manifestações.

Esta pesquisa, portanto, possui como corpus um recorte da letra do hino gospel "Eu cuido de Ti". Segundo (DOLGHIE, 2016, p.85) a "definição do conceito de hino gerou estudos e algumas controvérsias desde cristãos primitivos, passando pelos Concílios e chegando ao protestantismo". Por isso, nesta pesquisa serão utilizados também sinônimos para definir o uso melodioso cantado da linguagem.

O lançamento oficial do hino se deu no ano de 2016, fazendo parte de um álbum específico da autora que recebeu o mesmo título da canção, e se consagrou como um hino não-denominacional, ou seja, foi inserida e cantada em diversos cultos de práticas religiosas cristãs, principalmente, as de cunho protestante.

O objetivo deste estudo é investigar as avaliações no hino "Eu cuido de ti", para isso, utilizaremos o sistema de avaliatividade com ênfase no subsistema de atitude para compreender como a autora dispõe das seleções léxico-gramaticais ao longo do texto. Tendo em vista a realidade religiosa do cristianismo de base protestante e o aumento das

Revista do SELL, Uberaba/MG (online) - V. 9 n. 2, p.419- 434, jul./dez. - 2020. 
BORGES, G.S.C.; PARREIRA, F.A.S.D.

adesões a essas práticas religiosas no Brasil, o interesse em realizar esse tipo de pesquisa contribuirá para compreender os hinos evangélicos pela perspectiva analítica da LSF.

Uma vez que, as abordagens funcionais têm como objetivo básico a análise da eficiência na comunicação entre os usuários da língua, e estão apoiadas em três pontos básicos: o uso, o significado e o social. Segundo (SANTOS, 2009, p. 165):

Numa concepção geral, a perspectiva funcional tem como premissa básica de interesse a verificação como os usuários da língua se comunicam eficientemente em diversos contextos. Assim, os pontos principais que sedimentam as discussões dentro da perspectiva funcionalista na gramática proposta por Halliday e Matthiessen (2004) são: o uso (em relação ao sistema); o significado (em relação à forma) e o social (em relação ao indivíduo).

Posto isso, vale salientar que a LSF e sua metodologia de análise de dados, especificamente, no que tange a Avaliatividade foram usadas para o tratamento do corpus. Portanto, este artigo subdivide-se respectivamente em introdução e outras quatro seções sendo elas: LSF: as metafunções e seus estratos; o sistema de Avaliatividade; Atitude: um subsistema da Avaliatividade; Análises do corpus; considerações finais e referências.

\section{LSF: as metafunções e seus estratos}

A LSF compreende que a linguagem é utilizada para realizar trocas de significados, sobre isso Fuzer e Cabral (2014, p. 21), com base nos estudos de Halliday (1994), asseveram que: "Na perspectiva sistêmico-funcional, a linguagem é um recurso para fazer e trocar significados, utilizada no meio social de modo que o indivíduo possa desempenhar papéis sociais [...]".

Ao nos comunicarmos damos ênfase a determinadas escolhas ao invés de outras, e essas seleções que realizamos dentre as possibilidades disponíveis no nosso arcabouço linguístico possibilitam expressar as nossas opiniões, gostos, construção de experiências, etc. Desse modo, a LSF concebe o texto como uma unidade semântica, pois segundo Bárbara e De Macedo (2009, p. 90), “Trata-se de uma teoria que parte do significado e não da forma. Tendo em vista que a unidade semântica é o texto, seu ponto de partida (e não a oração), apresenta-se, portanto, como uma teoria da comunicação humana".

Assim, com cada contexto agimos de forma apropriada, realizamos escolhas paralinguísticas para nos comunicar, a LSF considera essas escolhas léxico-gramaticais de acordo com as intencionalidades que deseja atingir. De acordo com Fuzer e Cabral (2014, p. 19):

A teoria sistêmico-funcional busca identificar as estruturas de linguagem específicas, que contribuem para o significado de um texto e que, portanto, 
as análises que se realizam nessa perspectiva teórica se propõem a mostrar como e por que um texto significa o que significa.

Neste sentido, a língua é vista, pela LSF, como um sistema semiótico que possui o objetivo de satisfazer as necessidades da comunicação humana e, por isso, é organizada de maneira funcional e sistêmica. Halliday e Matthiessen (2004) afirmam que ela é estruturada para produzir três principais tipos de significados simultaneamente, que Halliday (1994) chama de metafunções. As metafunções são classificadas, conforme suas manifestações, em:

i) ideacional, que constrói a experiência humana, tendo em vista que não há faceta da experiência humana que não possa ser transformada em significado. A metafunção ideacional é subdividida em dois componentes, o experiencial e o lógico; ii) interpessoal, que se refere à linguagem como ação, já que ela ordena nossas relações pessoais e sociais com as outras pessoas; e iii) textual, que permite a construção de sequências de discurso, a organização do fluxo discursivo e a criação da coesão e da continuidade ao longo do texto. (OLIVEIRA, 2014a, p. 3, grifos do autor).

As metafunções são apresentadas teoricamente de acordo com a função distintiva e de forma isolada, porém, para Halliday (1994) como afirma (OLIVEIRA, 2014a, p. 3), elas atuam em conjunto e são simultaneamente auxiliadas pelas construções léxicogramaticais em um determinado texto contribuindo para a formação de seus significados.

Está claro que as três metafunções não atuam de maneira isolada ou independente na língua, mas interagem entre si com o intuito mais amplo de construir o significado do texto. Além disso, as metafunções relacionam-se diretamente com a estrutura léxico-gramatical do texto, o que, consequentemente, vai influenciar na estrutura da oração de maneira mais específica.

Portanto, Vian Jr (2010, p. 21) apoiado em Halliday (1994), explica que a teoria Sistêmico-Funcional considera, basicamente, que os sistemas linguísticos podem ser subdivididos em três estratos, sendo eles: o grafo-fonológico, o léxico-gramatical e o semântico-discursivo, ou seja, os níveis que compreendem respectivamente, a) as letras/sons; b) os fraseados e c) os significados. A figura 1, a seguir, representa a forma organizacional destes estratos de acordo com os preceitos teóricos da LSF de Halliday (1994). 
Figura 1: Estratos da linguagem, segundo a LSF.

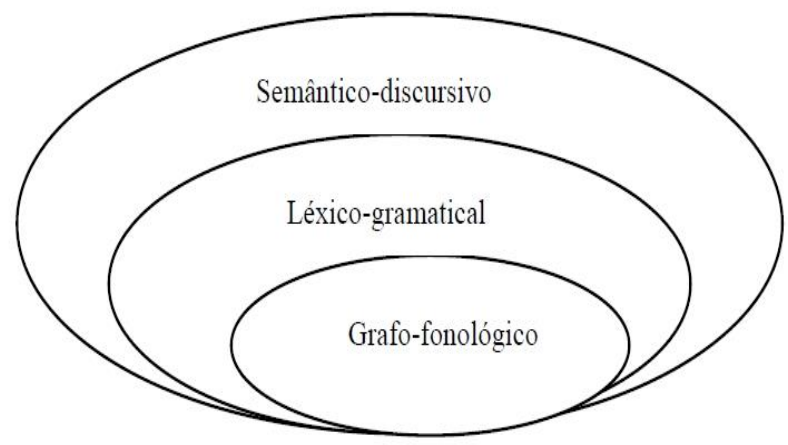

Fonte: (VIAN JR, 2010, p. 21).

De acordo com Fuzer e Cabral (2014), o uso da LSF na análise de diferentes formas textuais tem levado ao desenvolvimento de outras teorias como, o Potencial de Estrutura Genérica (HASAN, 1989); a Teoria de Gênero e Registro (EGGINS; MARTIN, 1997); a Análise Crítica do Discurso (FAIRCLOUGH, 1992, 1993, 2001); a Gramática do Design Visual (KRESS; VAN LEEUWEN, 1996 [2006]) e o Sistema de Avaliatividade (MARTIN; WHITE, 2005) entre outras; sendo esta última abordagem a que será usada como referência para o desenvolvimento desta pesquisa.

\section{O sistema de avaliatividade}

Fundamentada na LSF, com base, mais especificamente, no trabalho de Martin e White (2005), a Avaliatividade, do original Appraisal, é uma abordagem cuja finalidade é analisar e avaliar os significados interpessoais em diferentes textos e em contextos de situações e culturas diversas.

Vian Jr. (2010, p. 22) assevera que:

Ao selecionar o léxico avaliativo quando julgamos algo, partimos de sistemas semânticos, que são realizados léxico-gramaticalmente de forma a reforçarmos, ampliarmos ou minorarmos, reduzirmos, aquilo que avaliamos. Pode-se dizer, assim, que o Sistema de Avaliatividade caracteriza-se como um sistema interpessoal no nível da semântica do discurso que está articulado, simultaneamente, a outros dois sistemas, Negociação e Envolvimento e, em um nível superior de abstração, está relacionado à variável de registro Relações.

Desde a constituição da vida comunitária e seu desenvolvimento tanto sociocultural, quanto ideológico e político, o ser humano tem buscado uma forma de expressar os seus sentimentos, pensamentos, opiniões e comportamentos por diferentes formas de linguagem. Sobre essa temática, Oliveira, (2014b, p. 246) esclarece que:

Diariamente, nos eventos comunicativos, falantes/escreventes expressam pensamentos, sentimentos, opiniões e atitudes sobre algum objeto, 
BORGES, G.S.C.; PARREIRA, F.A.S.D.

fenômeno, evento, pessoa, etc. Em outras palavras, desde o nascer ao pôr do sol, o ser humano dotado da faculdade da linguagem está constantemente avaliando e sendo avaliado.

Em seu pensamento, sobre o ato de avaliar e ser avaliado, Oliveira (2014b, p. 247) diz que, os falantes de uma língua têm a seu dispor "recursos léxico-gramaticais e semântico-discursivos que lhes possibilitam não só fazer avaliações como também fazêlas em diferentes graus de intensidade, de acordo com suas percepções de mundo (crenças, valores) e intenções." Isso lhes permite realizar ou desempenhar um movimento discursivo expondo seu papel social, por meio de tais elementos avaliativos. Posto isso, o que se pode concluir, segundo esse autor, é que "[...] em maior ou menor grau de intensidade, estamos constantemente avaliando e sendo avaliados. Avaliar, portanto, é intrínseco à realidade humana" (OLIVEIRA, 2014b, p. 247).

De modo que, para Nunes e Cabral (2013, p. 251) "O Sistema de Avaliatividade investiga, por intermédio dos usos da linguagem, o modo como falantes/escritores atribuem valores a objetos, fenômenos e eventos". Barbara e De Macedo (2009, p. 95), indicam que este sistema torna possível investigar os padrões sociais semióticos, pois ele é "uma maneira de entender uma sociedade é analisar os textos por ela produzidos porque é pela linguagem que o indivíduo revela seus valores e suas representações".

Segundo Nunes e Cabral (2013), o Sistema de Avaliatividade é dividido em três subsistemas principais: Atitude, Engajamento e Gradação. Para Martin e White (2005), cada um desses campos é considerado como uma região de significados. Sobre essa questão, Vian Jr. (2010, p. 20), ressalta que, "[...] ao fazermos uma avaliação, também selecionamos o quanto queremos amplificá-la [...]", ou seja, é no procedimento avaliativo que o alcance do que se quer expressar pode ser regulado por meio da léxico-gramática.

\section{Atitude: um subsistema da avaliatividade}

A Atitude, na perspectiva do Sistema de Avaliatividade, torna-se um subsistema semântico-discursivo e está subdividido em três grupos de avaliação: a) Afeto, b) Julgamento e c) Apreciação. Conforme é ilustrado na figura 2, abaixo:

Figura 2: Subdivisão do Subsistema de Atitude

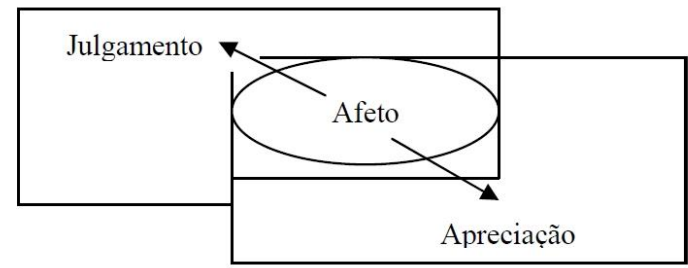

Fonte: Adaptado de Vian Jr (2010, p. 21).

Revista do SELL, Uberaba/MG (online) - V. 9 n. 2, p.419- 434, jul./dez. - 2020. 
Então, de acordo com a LSF, o afeto está relacionado com as reações emocionais presentes na linguagem, para Vian Jr. (2010, p. 20) "O afeto, dessa forma, é o centro das atitudes que expressamos". O exemplo 1, abaixo aponta como 0 afeto pode ser encontrado nas orações.

Exemplo 1: (...) eu não gosto [Felicidade-]... de três alunos no grupo. (ALMEIDA, 2010, p.79).

O afeto está diretamente relacionado às nossas emoções. Martin e White (2005) elucidam que ele pode ser explicitamente ou implicitamente expressado e que o estado emotivo são reações do contexto externo que implicam diretamente no indivíduo.

Martin e White (2005) classificam as emoções em três conjuntos principais, sendo eles: In (felicidade), In (segurança) e In (satisfação). O primeiro diz respeito às nossas emoções relacionadas diretamente com o emocional, tem a ver se o indivíduo está triste ou feliz, ansioso, com raiva, etc. O segundo é responsável por expressar as emoções relacionadas ao bem estar social, diz respeito à confiabilidade, ansiedade, dentre outros fatores externos que nos afetam. Por último, temos a In (satisfação), Almeida (2010, p. 51) baseada nos estudos de Martin e White (2005) assegura que essa categoria é um: "Conjunto que abrange as emoções relacionadas aos objetivos realizados: tédio, desprazer/desagrado, curiosidade, respeito."

O julgamento avalia o comportamento segundo as normas sociais, gerando os conceitos de estima social e sanção social e a apreciação para os recursos utilizados na avaliação dos elementos materiais. Conforme Vian Jr. (2010, p. 20) "[...] o julgamento refere-se ao universo das propostas sobre o comportamento e a apreciação ao universo das proposições sobre o valor das coisas." Como indicado no exemplo 2:

Exemplo 2: (...) Eu tenho essa experiência [julg: capacidade +]. (ALMEIDA, 2010, p.97).

Já a Apreciação, Almeida (2010, p. 100), afirma também que: "diz respeito às avaliações sobre as coisas e os objetos, no âmbito da estética, da forma, etc." como mostrado no exemplo 3 , a seguir.

Exemplo 3: Tem que ter todos os questionamentos, né? O estudo mais aprofundado [Valoração +]. (ALMEIDA, 2010, p.117). 
BORGES, G.S.C.; PARREIRA, F.A.S.D.

Ainda a autora aponta que estes subgrupos transitam quanto às questões que envolvem a polaridade, a modulação e a modalização, seja, positiva ou negativa (ALMEIDA, 2010), podendo ser intensificadas ou não e podem ser encontradas tanto em sua forma explicita quanto implícita (IKEDA, 2010). Considerando os aspectos estudados até o momento, pode-se perceber que, de acordo com o sistema de avaliatividade, a posição social, cultural, política e ideológica se relacionam intrinsecamente à língua/ linguagem.

As escolhas que realizamos para nos comunicar não ocorrem aleatoriamente, a todo o momento realizamos escolhas linguísticas que atendem às nossas necessidades comunicativas. Então, como já exposto na seção anterior, as nossas avalições estão diretamente relacionadas ao contexto que estamos inseridos, ao grupo de falantes/escritores que estamos direcionando a nossa fala e as intencionalidades que se deseja alcançar.

A categoria de apreciação é responsável por expressar as nossas avaliações sobre coisas e objetos, Almeida (2010, p. 57) explicita que: "A apreciação é realizada pelos elementos léxico-gramaticais bem como pelas orações completas. Ambas as palavras podem codificar a expressão de gostos e desgostos e a nossa avaliação sobre as pessoas, objetos, ou entidades." Martin e White (2005) esclarecem as formas léxicogramaticais como: Nominalização, Composição (Composição equilíbrio, Composição complexidade), Reação (Reação de impacto, Reação-qualidade), Valoração.

Almeida (2010, p. 57) em consonância com os estudos de Eggins e Slade (1997) elucida sobre nominalização que: "[...] transformação de epítetos em objetos ou coisas. Como por exemplo: loveliness/horror; elegance/dagginess”. Expressar a apreciação pelos nomes permite um significado mais intenso. Podemos afirmar que há uma intensificação das escolhas léxico-gramaticais realizadas por meio das nominalizações e isso resulta em avaliações mais intensas.

A composição expressa as nossas reações às coisas e objetos, e é dividida em Reação impacto e Reação-qualidade. A primeira diz respeito ao objeto nos agradar ou não, a segunda tem a ver com a qualidade do objeto, se usa geralmente a pergunta: isso Ihe agradou? A outra forma léxico-gramatical é a Composição, que está diretamente ligada com as percepções e proporções, e está dividida em duas partes: Composição equilíbrio que tem a ver com proporcionalidade e Composição complexidade que tem a ver ao quão complexo é o objeto. Por último, Martin e White (2005) apontam a Valoração, que corresponde ao valor que atribuímos a coisas e objetos. 
BORGES, G.S.C.; PARREIRA, F.A.S.D.

$\mathrm{Na}$ seção seguinte realizamos as análises do corpus, mostramos os procedimentos de análise, e a descrição do contexto que a cantora/autora está inserida.

\section{Análises do corpus}

Nesta seção, analisaremos os trechos do hino de acordo com o sistema de avaliatividade, com ênfase no subsistema de atitude. Após a leitura detalhada do hino, selecionamos os trechos que continham algum tipo de avaliação. Após esta fase, classificamos cada trecho de acordo com o subtipo do sistema de avaliatividade. É importante destacar que, os trechos que contem avaliação estão destacados em negrito.

O corpus deste trabalho é a música "Eu cuido de ti" composto e interpretado pela cantora Cláudia Canção. Com o intuito de facilitar a compreensão do hino no todo, optamos por colocar a letra completa, e selecionar os trechos para análise.

\section{Eu Cuido de Ti}

Quando todos os meus medos já não cabem mais em mim Quando o céu está de bronze e parece que é o fim Quando o vento está revolto e o mar não quer se acalmar Quando as horas do relógio se demoram a passar

Muitas vezes não consigo os teus planos compreender Mas prefiro confiar sem entender

Eu creio em $\mathrm{Ti}$
Eu creio em $\mathrm{Ti}$
Eu olho pra $\mathrm{Ti}$
E espero em $\mathrm{Ti}$

Quando você sente medo, do teu lado Eu estou $E$ é bom que você saiba que Eu sinto a tua dor Nunca, nunca se esqueça que o mar posso acalmar E que Eu sei o tempo certo da vitória te entregar

Este tempo é necessário pra te amadurecer E depois tem novidade pra você

Eu cuido de $\mathrm{Ti}$

Eu cuido de $\mathrm{Ti}$ Descansa em mim Comece a sorrir

O que Eu tenho é bem melhor

Pois só Eu sei do amanhã

Então recebe o abraço Meu

Pois da tua vida cuido Eu

Eu cuido de $\mathrm{Ti}$

Eu cuido de $\mathrm{Ti}$

Descansa em mim

Comece a sorrir 
BORGES, G.S.C.; PARREIRA, F.A.S.D.

Ao iniciar a música, a autora utiliza a circunstância de localização de tempo 'quando' para indeterminar a temporalidade. Mas que no trecho 2, essa temporalidade pode ser determinada pelo uso do atributo formado pelos processos materiais transformativos de movimento: modo e movimento: lugar 'demoram a passar' que indicam uma reação-qualidade negativa.

Trecho 1: Quando todos os meus medos já não cabem mais em mim. (Segurança) Trecho 2: Quando as horas do relógio se demoram a passar. (Reação-qualidade-)

Conforme assinala Almeida (2010, p. 30): “[...] (1) Processos materiais: processos do fazer. Representam as ações do campo físico realizadas por um ator ou um evento. O significado básico desse processo é que alguém ou alguma coisa realiza uma ação [...]." Assim, no trecho 1, ela se autoavalia negativamente por meio de afeto de insegurança ao exprimir seus sentimentos pelo uso da nominalização 'medo' juntamente com 'já não cabem mais' que, contém o processo material transformativo de tamanho 'cabem' intensificado pelo uso do 'mais'.

Trecho 3: Quando o céu está de bronze e parece que é o fim. (Reação-impacto-)

Nota-se que há uma avaliação de apreciação negativa de valoração, por meio do processo relacional atributivo 'está' e do epíteto "bronze" relacionando a cor aos sentimentos negativos, o que indica uma polaridade negativa implícita na avaliação, associada aos processos relacionais intensivos 'parecer' e 'é'. Já a nominalização 'o fim' refere-se à ideia de falta de possibilidades, ou seja, a autora reconhece que na vida humana, sobretudo a do cristão, há momentos de desesperança, que se classifica como uma apreciação de reação-impacto.

Trecho 4: Quando o vento está revolto e o mar não quer se acalmar (Reação-impacto)

No trecho 4, as nominalizações "vento" e "mar" evidenciam o papel social cristão, sua identificação e posicionamento diante de problemas cotidianos, sejam, sociais ou individuais ao considerar os padrões comunitários que levam a um sentimento de unidade entre os fiéis. O emprego do processo relacional atributivo 'está' e do atributo 'revolto', formado por meio do adjunto modal de polaridade negativa 'não' associado aos processos mentais, desiderativo 'quer' e emotivo 'acalmar' indicam uma apreciação negativa reação- 
BORGES, G.S.C.; PARREIRA, F.A.S.D.

impacto quanto à percepção da realidade gregária em que este cristão está imerso, e que esta é passível de frustações, angústias e outros males, mesmo que eles sigam um comportamento religioso considerado adequado, mas que precisam se apoiar em suas crenças, como veremos adiante.

Isso ocorre, justamente, por meio de escolhas léxico-gramaticais mais genéricas que visam estabelecer uma resposta de solidariedade às práticas religiosas cristãs, uma vez que de acordo com Morais e Barbara (2018, p. 75) este se torna "um recurso poderoso".

Trecho 5: Muitas vezes não consigo os teus planos compreender (Capacidade-) mas prefiro confiar (Reação-impacto+) sem entender. (Capacidade-)

Já no trecho 5, notamos uma avaliação de autojulgamento, pois observamos que o que considerado é o locutor, a avaliação é considerada de estima social do tipo capacidade de polaridade negativa, uma vez que, para Almeida (2010, p. 53) os julgamentos são "normas de comportamento que direcionam as pessoas como devem ou não agir".

Podemos constatar que a polaridade negativa 'não' vinculada ao processo mental 'consigo' está relacionado a relação da autora e a divindade. Notamos que é expresso um sentimento de inferioridade humana baseada em sua crença e nas coisas que a autora acredita, desse modo, nos transparecem a sensação de limitação diante da grandeza da relação dela com Deus. No trecho 'os teus planos compreender', a autora explicita sua incompreensão sobre as possibilidades que a sua relação com Deus expressa. Constatamos que trata de sentimentos abstratos que são expressos no hino, essa relação entre a autora e Deus contemplam as necessidades da mesma em exteriorizar suas experiências.

Posto isso, a autora utiliza a conjunção adversativa, 'mas' junto ao processo mental desiderativo flexionado em primeira pessoa do singular no presente do indicativo 'prefiro' para expressar sua inclinação à resignação pessoal de seus desejos e competências. Observamos que, a entidade assume um papel soberano sobre a vida do sujeito, que a evoca, principalmente, pelo uso do processo mental cognitivo 'confiar'. Compreendemos que caracteriza uma apreciação de reação-impacto positiva, quanto à atuação do ser divino na vida desse indivíduo, mesmo que esse se julgue sem aptidão para exercer sua crença o que é explicitado pelo 'sem' e pelo processo mental cognitivo 'entender', ou seja, capacidade negativa. 
Trecho 6: Eu creio em ti, eu creio em ti, eu olho pra ti, E espero em ti (Reação-impacto+)

No trecho 6, a autora expressa sua avaliação pelo subsistema denominado apreciação, que se encontra intensificado pelo uso do recurso gramatical anafórico 'eu creio em ti' que traz à tona a reafirmação da crença sobrenatural em uma determinada divindade ao empregar o processo mental cognitivo em primeira pessoa do singular ‘creio'. Nesse caso, o processo mental 'creio' representa a percepção da autora sobre a sua crença na divindade, compreendemos que a escolha desse processo demonstra que a autora ressalta a importância da fé em sua vida. Isso revela uma reação-impacto positiva quando, na canção, o humano se relaciona empaticamente com a divindade, em que esta também partilha suas emoções buscando sanar o compromisso idealizado.

O indivíduo corporifica a entidade invisível no processo mental perceptivo 'olho' em que surge uma relação contemplativa do divino que se coloca para esse participante, em uma relação interativa, mas ao mesmo tempo passiva. Sobre os processos transformativos Fuzer e Cabral (2014, p. 47) "Nas orações transformativas, o resultado é a mudança de algum aspecto de um participante já existente. O Ator ou a Meta, que preexistem, são transformados, tendo como resultado a troca ou alteração de algum aspecto do mundo físico [...]."

Nota-se pelo uso do processo material transformativo de movimento: lugar, representado pela escolha linguística 'espero', nos demonstra que o participante, no caso, a autora, identificado pelo pronome 'eu', avalia positivamente a sua relação de estar em sintonia com Deus. Os processos: 'creio, olho, espero', demonstram que a relação de crer e aguardar com confiança na divindade é uma característica pertinente no hino.

\section{CONSIDERAÇÕES FINAIS}

Esta pesquisa teve como finalidade chamar a atenção sobre as possibilidades de leitura e avaliação em um texto de acordo com o estrato semântico-discursivo e a estrutura teórica da LSF (HALLIDAY, 1994), mais especificamente, o sistema de Avaliatividade (MARTIN; WHITE, 2005).

Além disso, buscou-se compreender esse sistema sob os aspectos de seus subgrupos afeto, julgamento, apreciação e que estes podem ser encontrados de forma explícita ou implícita permitindo exercer as avaliações de acordo com os graus de polaridade e intensificação. O que possibilita ampliar as análises do comportamento 
BORGES, G.S.C.; PARREIRA, F.A.S.D.

humano em relação ao seu papel e conduta sociais intrinsecamente ligadas à produção musical gospel.

Por meio das análises realizadas foi possível identificar e reconhecer construções léxico-gramaticais que produzem a significação do papel social do cristão protestante. Visto que esse grupo religioso traz em seus cânticos a relação com sua divindade e crenças que incorporam suas experiências de mundo, ao mesmo tempo em que estabelece relações com seus possíveis interlocutores.

Pode-se depreender quanto às análises, que a filosofia cristã ocidental adotada pelas comunidades protestantes brasileiras reproduz em seu discurso a experiência do indivíduo perante a divindade e à vida, sendo esta última vista como lugar de experiências negativas, por isso, em sua grande maioria as avaliações foram de reação-impacto negativas. Sendo a apreciação da divindade uma reação-impacto positiva que auxilia o ser humano a esperar por uma mudança de vida.

Então, de forma explícita em sua letra, a música 'Eu cuido de ti' indica um papel social inseguro e duvidoso de suas capacidades, exprimindo a fraqueza, o ser pecador, o humano que não compreende a ação de outro ser superior, mas que o aguarda com devoção que, implicitamente reproduz ao longo dos anos o ideal teocêntrico que perdura em práticas religiosas na contemporaneidade.

\section{REFERÊNCIAS}

ALMEIDA, F. S. D. P. Atitude: afeto, julgamento e apreciação. In: VIAN JR, O.; SOUZA, A. A. de; ALMEIDA, F. S. D. P. A linguagem da avaliação em língua portuguesa: estudos sistêmico-funcionais com base no sistema de avaliatividade. São Carlos: Pedro \& João Editores, 2010.

BARBARA, L.; DE MACÊDO, C. M. M. Linguística Sistêmico-Funcional para a análise de discurso: um panorama introdutório. Cadernos de linguagem e sociedade, v. 10, n. $1,2009$.

CANÇÃO, C. Eu cuido de ti. Revista digital Comunhão. Vitória - ES, Paulino Muller. Abril 2016. Disponível em:<https://comunhao.com.br/dupla-cancao-e-louvor-fala-sobre-eucreio-em-ti/. Acesso em: 07 de Dezembro de 2020.

DOLGHIE, J. Z. Um estudo sobre a formação da hinódia protestante brasileira. Âncora rev. digital de estudos em religião. 2016. p.83-106. Disponível em: http://www.hinologia.org/um-estudo-sobre-a-formacao-da-hinodia-protestante-brasileirajacqueline-ziroldo-dolghie/. Acesso em: 27 de abr. de 2020.

EGGINS, S.; MARTIN, J. R. Genres and registers of discourse. In: DIJK, T. V. (Ed.). Discourse as structure and process - discourse studies: a multidisciplinary introduction. v. 1. London, Thousand Oaks, New Delhi: Sage Publications, 1997. 
BORGES, G.S.C.; PARREIRA, F.A.S.D.

EGGINS, S.; SLADE, D. Analizing casual conversational. Cambridge: Cassel, 1997.

FAIRCLOUGH, N. Discurso e mudança social. Brasília: Editora da UNB, 2001.

FAIRCLOUGH, N. Critical discourse analysis in the marketization of public discourse: the universities. Discourse \& society, vol. 2, ㄲo 4, p.133- 168, 1993.

FAIRCLOUGH, N. Discourse and social change. Cambridge UK: Polity Press, 1992.

FUZER, C.; CABRAL, S. R. S. Introdução à gramática sistêmico-funcional em língua portuguesa. Campinas: Mercado de Letras, 2014.

HALLIDAY, M. A. K. An introduction to Functional Grammar. 2. ed. London: Edward Arnold, 1994.

HALLIDAY, M. A. K; MATTHIESSEN, C. M. I. M. An introduction to Functional Grammar. 3. ed. London: Hodder Arnold, 2004.

HASAN, R. Language, context, and text: aspects of language in a social-semiotic perspective. Oxford: Oxford University Press, 1989.

IKEDA, S. N. O julgamento na argumentação de um editorial. In: VIAN JR, O.; SOUZA, A. A. de; ALMEIDA, F. S. D. P. A linguagem da avaliação em língua portuguesa: estudos sistêmico-funcionais com base no sistema de avaliatividade. São Carlos: Pedro \& João Editores, 2010.

KRESS, G.; VAN LEEUWEN, T. Reading images: the grammar of visual design. London, New York: Routledge, [1996], 2006.

MARTIN, J. R.; WHITE, P. The language of evaluation: appraisal in English. New York: Palgrave, 2005.

MORAIS, F. B. C. de; BARBARA, L. O uso de nominalização como recurso de impessoalização em artigos escritos em língua portuguesa: um estudo com base na linguística sistêmico-funcional. Cadernos de Linguagem e Sociedade, v. 19, n. 1, p. 7391, 2018.

NUNES, G. G.; CABRAL, S. R. S. Avaliatividade e julgamento: uma análise de texto. Nonada: Letras em Revista, v. 1, n. 20, 2013.

OLIVEIRA, D. O sistema de avaliatividade do editorial da revista caros amigos. Revista Entremeios: revista de estudos do discurso. n. 8, 2014a. Disponível em: < http://www.entremeios.inf.br/published/156.pdf>. Acesso em: 07 de dezembro de 2020.

OLIVEIRA, D. O Sistema de Avaliatividade: aspectos teóricos e práticos. Revista Fórum Identidades, 2014b. Disponível em: < https://seer.ufs.br/index.php/forumidentidades/article/view/3037>. Acesso em: 09 de dezembro de 2020.

SANTOS, Z. B. Aspectos semióticos e lexicogramaticais de peças publicitárias: a construção de uma leitura multimodal. Dissertação (Mestrado em Linguística do Texto e do Discurso.) - Universidade Federal de Minas Gerais, Belo Horizonte, 2009. Disponível 
BORGES, G.S.C.; PARREIRA, F.A.S.D.

em: <https://repositorio.ufmg.br/bitstream/1843/LETR-8T9QPR/1/disser1.pdf>. Acesso em: 08 de Dezembro de 2020.

VIAN JR. O. O Sistema de Avaliatividade e a linguagem da avaliação. In: VIAN JR, O.; SOUZA, A. A. de; ALMEIDA, F. S. D. P. A linguagem de avaliação em língua portuguesa: estudos sistêmico-funcionais com base no sistema de avaliatividade. São Carlos: Pedro e João Editores, 2010.

VIAN JR, O.; SOUZA, A. A. de; ALMEIDA, F. S. D. P. A linguagem de avaliação em língua portuguesa: estudos sistêmico-funcionais com base no sistema de avaliatividade. São Carlos: Pedro e João Editores, 2010.

\section{Como citar este artigo (ABNT)}

BORGES, G.S.C.; PARREIRA, F.A.S.D. Uma análise do hino "EU cuido de TI" com base na teoria da linguística sistêmico-funcional e do sistema de avaliatividade. SELL, Uberaba, MG, v. X, n. X, p. XXX-XXX, 2019. Disponível em: <inserir link de acesso>. Acesso em: inserir dia, mês e ano de acesso. DOI: inserir link do DOI.

Como citar este artigo (APA)

Borges, G.S.C., \& Parreira, F.A.S.D. (2020). Uma análise do hino "EU cuido de TI" com base na teoria da linguística sistêmico-funcional e do sistema de avaliatividade. SELL, $X$ (X), XXX-XXX. Recuperado em: inserir dia, mês e ano de acesso de inserir link de acesso. DOI: inserir link do DOI. 